\title{
A MODEL FOR DESIGNING AND EVALUATING TEACHER TRAINING PROGRAMS IN TECHNOLOGY EDUCATION
}

\author{
Justus J. Randolph, Marjo Virnes and Pasi J. Eronen \\ Educational Technology Research Group, Department of Computer Science, University of \\ Joensuu, P.O.Box 111, FIN-80101 Joensuu, FINLAND.E-mail: justusrandolph@yahoo.com, \\ \{mvirnes, peronen\}@cs.joensuufi
}

\begin{abstract}
This paper describes a model that was successfully used for the simultaneous design and evaluation planning of a Finnish teacher training program in technology education that was carried out via computer-mediated learning. An argument for simultaneous program design and evaluation planning is given.
\end{abstract}

Key words: program design, program evaluation, technology education

\section{INTRODUCTION}

Given the enormous scope and complexity of the work that program designers and evaluators do, systematic, yet adaptable, models for accomplishing their tasks are essential. This paper outlines a step-by-step model that was used for the simultaneous design and evaluation planning of the Development Project for Educational Technology (DPET). It is hoped that this simultaneous program design and evaluation planning model will be a useful template for those who have been charged with designing and evaluating similar programs.

The DPET program, which develops theory, best practices, and pedagogical tools in technology education, is a three-year program (20032005) supported by the European Social Fund. The first year of the program was dedicated to developing concepts of technology education in the Kids' Club research laboratory (Eronen et al., 2002), developing educational tools 
(e.g., programming environments), and providing supplementary teacher education. The purpose of the supplementary education component is to increase teachers' ICT knowledge and skills so that they can take advantage of modern educational technology tools and methods in their classes. The model described here was used for the program design and evaluation planning of the supplemental teacher education aspect of DPET.

Of the many overt and covert purposes for evaluation, using evaluation as an aid to program design has been largely overlooked. This is surprising since simultaneous program design and evaluation planning brings forth mutually beneficial results.

In short, evaluation planning and program design facilitate one another. First, through preliminary evaluation activities, program goals are clarified. Second, evaluation planning helps determine the appropriate measures of progress toward program goals. Those measures can then be used as guidelines for planning program activities. Similarly, the quality of evaluation is increased when the program is designed to accommodate empirically-grounded research designs.

\section{DESCRIPTION OF THE SIMULTANEOUS PROGRAM DESIGN AND EVALUATION PLANNING MODEL}

The following section describes the model used for the evaluation of the DPET program. The preliminary activities - (a) establishing the program context and rationale, (b) creating a logic model, (c) developing a stakeholder and (d) human participants matrix - are activities that benefit both the evaluation planning and program design process. The (e) evaluation planning and (f) program design steps, although they are separate entities, are complementary. The concluding and iterative steps - $(\mathrm{g})$ developing implementation plans, (h) reporting plans, (i) monitoring plans, (j) data collection, analysis, reporting, and $(\mathrm{k})$ modification and meta-evaluation are steps that are necessary for both evaluation and program success and can be conducted simultaneously. See Table 1 for an overview of the model. 
Table 1. Overview of the Simultaneous Program Design and Evaluation Planning Model

Procedural Steps in the Model

\begin{tabular}{|c|c|}
\hline $\begin{array}{r}\text { Prelim } \\
\text { Establishing Progra } \\
\text { Developin } \\
\text { Creating a S } \\
\text { Developing a Hun }\end{array}$ & $\begin{array}{l}\text { Steps } \\
\text { ntext and Rationale } \\
\text { gic Model } \\
\text { older Matrix } \\
\text { articipants Matrix }\end{array}$ \\
\hline Evaluation Planning Steps & Program Design Steps \\
\hline Compiling Divergent Questions & Creating Program Goals \\
\hline Deciding on Convergent Questions & Developing Indicators and Benchmarks \\
\hline Planning for Data Collection and Analysis & Designing Program Activities \\
\hline \multicolumn{2}{|c|}{ Concluding and Iterative Steps } \\
\hline \multicolumn{2}{|c|}{ Creating an Implementation Plan } \\
\hline \multicolumn{2}{|c|}{ Developing a Reporting Plan } \\
\hline \multicolumn{2}{|c|}{ Data Collection, Analysis, and Reporting } \\
\hline Program Modificat & d Meta-Evaluation \\
\hline
\end{tabular}

\subsection{Establishing the Program Context and Rationale}

The first step in this design and evaluation model is to gain knowledge of the context, background, and rationale for the program. Understanding the context aids program designers and evaluators, among other things, in making culturally appropriate decisions. Being aware of the program's background assists designers and evaluators in avoiding the mistakes that past program attempts have made. Finally, understanding the rationale of the program helps designers and evaluators concretize and clarify the task that has been put before them.

In the DPET program, program practitioners and designers gave short presentations about the history of the program, the long-term goals of the program, funder expectations, and how the program fits into the wider context of other activities and programs.

\subsection{Creating a Logic Model}

The next step in this model is the creation of a logic model. A logic model is a graphical representation of the causal links between the program and its intended outcomes. Creating a logic model has many benefits for clarifying and codifying conceptions of what the program is and how it works. Additionally, it can serve as a guideline for creating evaluation questions when the causal links between the program and the outcomes need to be investigated. 
Figure 1 is an example of the logic model created for the DPET program. It shows how the program is causally expected to lead to the desired outcomes - increased academic achievement and meaningful collaboration with the educational community.

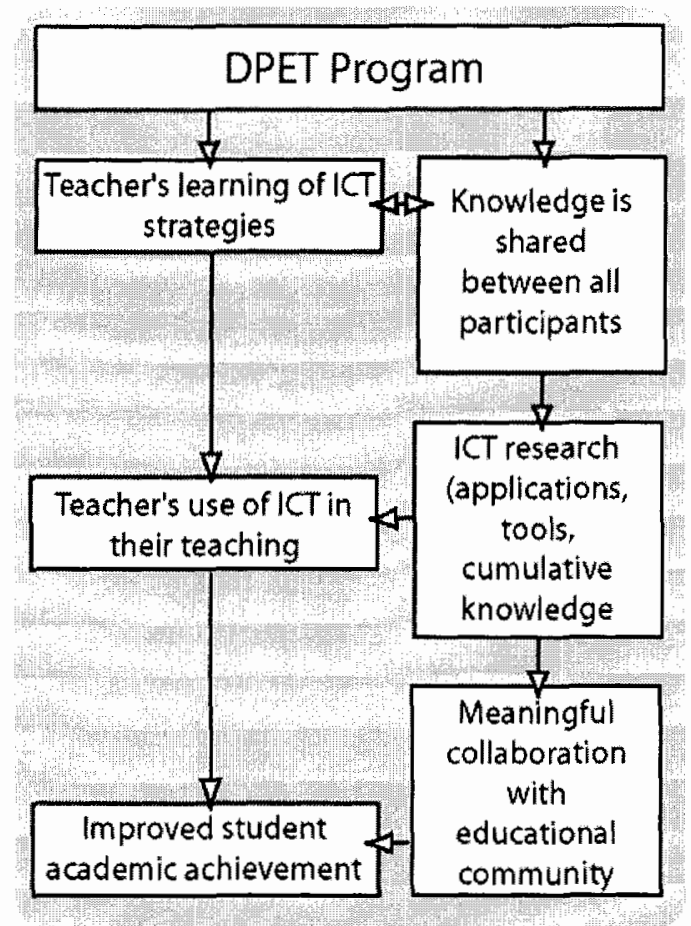

Figure 1. DPET Logic Model

\subsection{Developing a Stakeholder Matrix}

Creating a stakeholder matrix aids designers and evaluators in thinking about how the program will affect particular stakeholder groups. The stakeholder matrix is a document that should be considered often during the program design and evaluation process. For example, when developing divergent evaluation questions (i.e., comprehensive questions from all stakeholders), evaluation team members could roleplay what questions stakeholder groups might want answered about the program.

The first step in the creation of a stakeholder matrix is to brainstorm all of the groups that will be affected by the program. In the matrix, labels for the different stakeholder groups fill the rows while stakeholder questions fill the columns. Some of the questions asked for each stakeholder group are 
listed below. See Preskill and Torres (1999) for more examples of questions that concern stakeholders.

- How will this stakeholder group be affected?

- What are the benefits to stakeholders?

- What are the risks to stakeholders?

- What are the differential effects for stakeholders?

- Should this stakeholder group be involved in the planning, execution, and reporting of the program and its evaluation?

In the DPET program the stakeholder groups were:

- Teachers/teaching assistants

- Students

- Researchers/research community

- Parents

- University administrators

- University students

- Funders

- Regional government

- The host department (the Department of Computer Science)

\subsection{Creating a Human Participants Matrix}

The human participants matrix functions similarly to the stakeholder matrix except that the emphasis is on how stakeholders will be affected by the evaluation. The human participants matrix reduces the possibility of unethical treatment because the evaluators systematically consider each participant group in terms of a number of ethical considerations.

The process for creating a human participants matrix is similar to creating a stakeholder matrix. First, the designers and evaluators brainstorm which groups may participate in the evaluation of the program. Labels for these groups go into the rows of the matrix and the ethical questions go into the columns. Examples of ethical questions (see Berry \& Rubal, 2003) that could go into a human participants matrix are:

- Is scientifically sound action being taken regarding this stakeholder group?

- What are the risks to this group?

- What are the benefits to this group?

- Is there equitable participant selection? If not, why not?

- Are there vulnerable participants? 
- Will the results be confidential? Will the results be anonymous?

- Is informed consent needed?

- Are the participants fluent in the primary language of interaction?

\subsection{Evaluation Planning}

After the preliminary context-oriented steps, the core of evaluation planning can take place. In this model, evaluation planning involves three main activities - developing divergent questions, deciding on a list of convergent questions (i.e., a final list of questions selected from the list of divergent questions), and making evaluation plans for each of the convergent questions. It is helpful to carry out the evaluation planning activities and the program design activities concurrently.

\subsubsection{Developing Divergent Questions}

Developing divergent questions is a process of collecting all of the questions that stakeholders might want answered about the program. It is useful during this phase to elicit questions from the different stakeholder groups directly. If this is not feasible, members of the evaluation team could try to predict what questions different stakeholder groups might have. For example, in the DPET evaluation planning process it was impractical to contact all stakeholders groups so evaluation team members tried to predict the different questions that each main stakeholder group would want answered. Revisiting the logic model and creating questions about the causal links is also beneficial for creating evaluation questions. As an example, a sample of 5 questions from the 29 divergent questions from the DPET evaluation plan is listed below.

- Do teachers learn to teach technology because of this program? (research-oriented question)

- Are our research methods appropriate? (meta-evaluation question)

- How much time does it take to use technology in the classroom? (teacher-oriented question)

- How does what I learn help my life and future studies? (student-oriented question)

- How does the program affect the development of North Karelia? (funderoriented question)

\subsubsection{Deciding on Convergent Questions}

After the list of divergent questions is compiled, it is a matter of reducing the divergent questions to a convergent list of questions. The convergent 
questions will become the final list of evaluation questions. Each convergent question will have its own data collection plan.

Depending on the context of the evaluation, there are different ways of selecting the convergent questions. If democracy is the most important factor, stakeholders might vote on the questions. Otherwise, program designers and evaluators may just decide on the questions that are most important to answer given the amount of time and resources. In the DPET evaluation, of the 29 divergent questions, 7 questions were chosen to be investigated further as convergent questions.

Sometimes it is better to concentrate on answering a few evaluation questions well rather than attempting to answer a host of questions poorly. In addition, it is important to consider the ethics of human participation, via the human participants matrix, as variables weighed into the process of choosing convergent questions.

\subsubsection{Planning for Collecting and Analyzing Data}

For each convergent question, a plan for reporting, collecting, and analyzing data should be made. A worksheet like the one used in the DPET evaluation, as illustrated in Table 2, could be filled out for each convergent question.

Table 2. Example of DPET Data Collection Plan Worksheet

\begin{tabular}{|c|c|c|c|}
\hline Evaluation Question & Presentation/Report & Methodology plan & Action Plan \\
\hline $\begin{array}{l}\text { Do teachers learn to } \\
\text { teach technology } \\
\text { because of the } \\
\text { training? }\end{array}$ & $\begin{array}{l}\text { Quantitative } \\
\text { comparisons of } \\
\text { mastery. Qualitative } \\
\text { self-reflection }\end{array}$ & $\begin{array}{l}\text { Give a pre-post } \\
\text { mastery checklist. } \\
\text { Interview teachers - } \\
\text { 'Did you learn to } \\
\text { teach technology } \\
\text { because of the } \\
\text { training?' }\end{array}$ & $\begin{array}{l}\text { Develop pre-post } \\
\text { checklist - Mid } \\
\text { January. Journal } \\
\text { entry - Teacher } \\
\text { evaluation activity } \\
\text { near end of course. }\end{array}$ \\
\hline
\end{tabular}

For each evaluation question, the evaluation team should envision how they would like to present the results. For example, evaluators could ask themselves, "Can we answer the question with a pie chart or is it better to report qualitative data?" Based on the desired presentation, a methodology plan is devised. The final column, the action plan, specifies who will do what at what time. It is helpful at this point to have evaluation team members or consultants who are versed in research methodology to assist at this point. Excellent resources for conducting this step were written by the National Science Foundation (2004), the OERL (2004), Preskill and Torres (1999), and Weiss (1996). 


\subsection{Program Design - Goals, Measurements, and Activities}

This section describes a method for designing program goals, measurements, and activities. A common method for designing programs is to start with the goals of the program. For each goal, measurements, indicators and benchmarks are determined. Indicators usually are considered long term or final results. Benchmarks, on the other hand, are milestones or periodic subindicators toward a larger goal. Benchmarks are useful when progress can be tracked over time. From the benchmarks and indicators, program activities are constructed. Activities are how the measurements will be affected which in turn indicate that the goals have been met. The logic of this strategy is that carrying out the program activities will lead to accomplishment of the indicators and benchmarks that show that the goals have been met. Revisiting the logic model is helpful for crafting the major and minor goals of a program.

The designers of the DPET program found it helpful to fill out a matrix, like the example illustrated in Table 3, to conceptualize the goals, measurements, and activities as part of the program design process.

Table 3. Program Design Table in DPET Program

Goals

Teachers become familiar with and can create a technology education curriculum in accordance with national standards

Teachers gain knowledge of student-level evaluation of technology education
Measures: Indicators, and/or

Benchmarks

Journaling: Meaningful reflection on the curriculum Teacher-made curriculum: Teachers can create a high quality curriculum

Teacher-made evaluation plans: Teachers can make or exhibit knowledge of valid and reliable measures of technology education

Teacher-made activity plan: Teachers have high quality activity plans (as rated by trainers)
Program Activities

Trainers facilitate discussion of the global, national, local (school) and individual curricula

Trainers present evaluation strategies and technologies
Teachers can create activities in accordance with the curriculum

\subsection{Creating an Implementation Plan}

The implementation plan concretizes how and when the different evaluation and program activities will be done. The appropriate method depends on the context and working history of the program designers. For 
the DPET program, the designers found it helpful to fill out a matrix with chronological program activities in the columns and with labels for the people expected to carry out the different aspects of the program in the rows.

\subsection{Creating a Reporting Plan}

Sustainability of the program and evaluation use are strongly correlated with the success of reporting program activities and results (Torres, Preskill, \& Piontek, 1996). Revisiting the stakeholder matrix and deciding on which, how, how often, and when each stakeholder group needs to be reported is a good strategy for creating a reporting plan. Although reporting is addressed in the plans for data collection and analysis, it is beneficial to have a separate reporting plan, that either complements or becomes a part of the implementation plan.

\subsection{Implementation Evaluation}

Implementation evaluation is important to verify that the program is being carried out as planned. As part of the DPET implementation evaluation, program designers made site visits to observe different aspects of program activities. Additionally, program designers were responsible for documenting and reporting the activities that occurred.

\subsection{Data Collection, Analysis, and Reporting}

After the data have been collected and analyzed, the results can be reported to the appropriate stakeholder groups according the reporting plan. Preskill and Torres (1999) suggest that evaluation use and the validity of conclusions drawn from the data can be increased by including stakeholders in the data collection, analysis, and reporting process.

\subsection{Program Modification and Meta-Evaluation}

Based on data collected from the evaluation, program designers may want to modify the program for a number of reasons. Since programs often have multi-year life spans, the modification and evaluation process should be thought of as an iterative process that occurs in cycles where each subsequent version of the program is an improvement on the last. Formal evaluation of outcomes usually is not appropriate until the program has had a chance to stabilize and mature. Programs go through developmental cycles and it is important to use the right kind of evaluation at the right time. 
Meta-evaluation is a term that simply means evaluation of an evaluation. The goal of meta-evaluation is to make subsequent evaluation cycles better than the previous cycles. One method for conducting a meta-evaluation is to create meta-evaluation questions based around the Guiding Principles for Evaluators (American Evaluation Association, 2004).

\section{CONCLUSIONS}

A detailed model for designing and evaluating teacher training programs in technology education was presented in this paper. It is not merely bound to its original context, but it can be applied to programs that are more general as well. Parts of the model are also useful in early program development. For example, the preliminary steps of the model are helpful in creating the plan for the program. Applying the plan throughout the program's lifespan helps standardize its activities, collect evaluation information, and develop the program through the continual analysis of evaluation data. It also allows the program's management to keep track of the program's progress. This model also serves as an explicitly stated road map for the program that helps practitioners know where they are heading at any given moment and what their tasks and duties are. It is also worth noting that the model is dynamic; the model itself can be improved and generalized to accommodate other units, treatments, outcomes, and settings through the practice of metaevaluation.

In the DPET program, this model helped designers create an explicitly stated framework for the program's goals, activities and evaluation. It helped the program to become more manageable. Especially, the clearly stated goals and their respective measures were helpful both for the program itself and for the research activities related to it. The only downside of the model is its heaviness when using it for the first time. It takes a relatively long time to go through all the steps so the design team must be committed to their work in order to have the best possible outcomes.

\section{ACKNOWLEDGEMENTS}

The authors wish to thank the European Social Fund (under grant ISLH2002-04159/Ha-7) and the Fulbright Center for Finnish-American Academic Exchange for their financial support. 


\section{References}

American Evaluation Association, 2004, Guiding Principles for Evaluators, (February 18, 2004); http://www.eval.org/EvaluationDocuments/aeaprin6.html.

Berry, E.H., and Rubal. T., 2003, Investigator's Handbook: A Guide for Human Participants in Research, Utah State University, (February 18, 2004); http://www.usu.edu/vpr/policies/resources.asp

Eronen, P. J., Sutinen, E., Vesisenaho, M., Virnes, M., Kids' Club as an ICT-Based Learning Laboratory. Informatics in Education - An International Journal, Vol. 1. Institute of Mathematics and Informatics, Vilnius, Lithuania, 2002, 61-72.

National Science Foundation, 2004, Resources for NSF Project Evaluation, (February 18, 2004), http://www.ehr.nsf.gov/rec/programs/evaluation/nsfresources.asp.

OERL, 2004, Online Evaluation Resource Library, (February 18, 2004), http://oerl.sri.com/.

Preskill, H. and Torres, R.T., 1999, Evaluative Inquiry for Learning in Organizations, Sage, Thousand Oaks, California.

Torres, R.T., Preskill, H.S., and Piontek, M.E., 1996, Evaluation Strategies for Communicating and Reporting: Enhancing Learning in Organizations, Sage, Thousand Oaks, California.

Weiss, C.H., 1998, Evaluation, 2nd ed., Prentice Hall, Upper Saddle River, New Jersey. 